\title{
Effects of geologic structures on organic carbon concentrations and thermal maturities in organic-rich Upper Devonian shales
}

Katherine Schmid and Antonette Markowski

Pennsylvania Geological Survey

www.denr.pa.gov

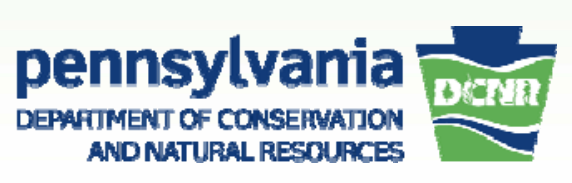




\section{Introduction}

- Predicting the effects of geologic structures on the distribution of organic carbon and development of thermal maturity in shales is important for oil and gas companies who want to develop drilling programs in organic-rich shales

- Shales need to contain at least 1\% TOC to produce hydrocarbons

- Shales need to reach a thermal maturity of about 0.6 to produce any oil or natural gas 


\section{Outline}

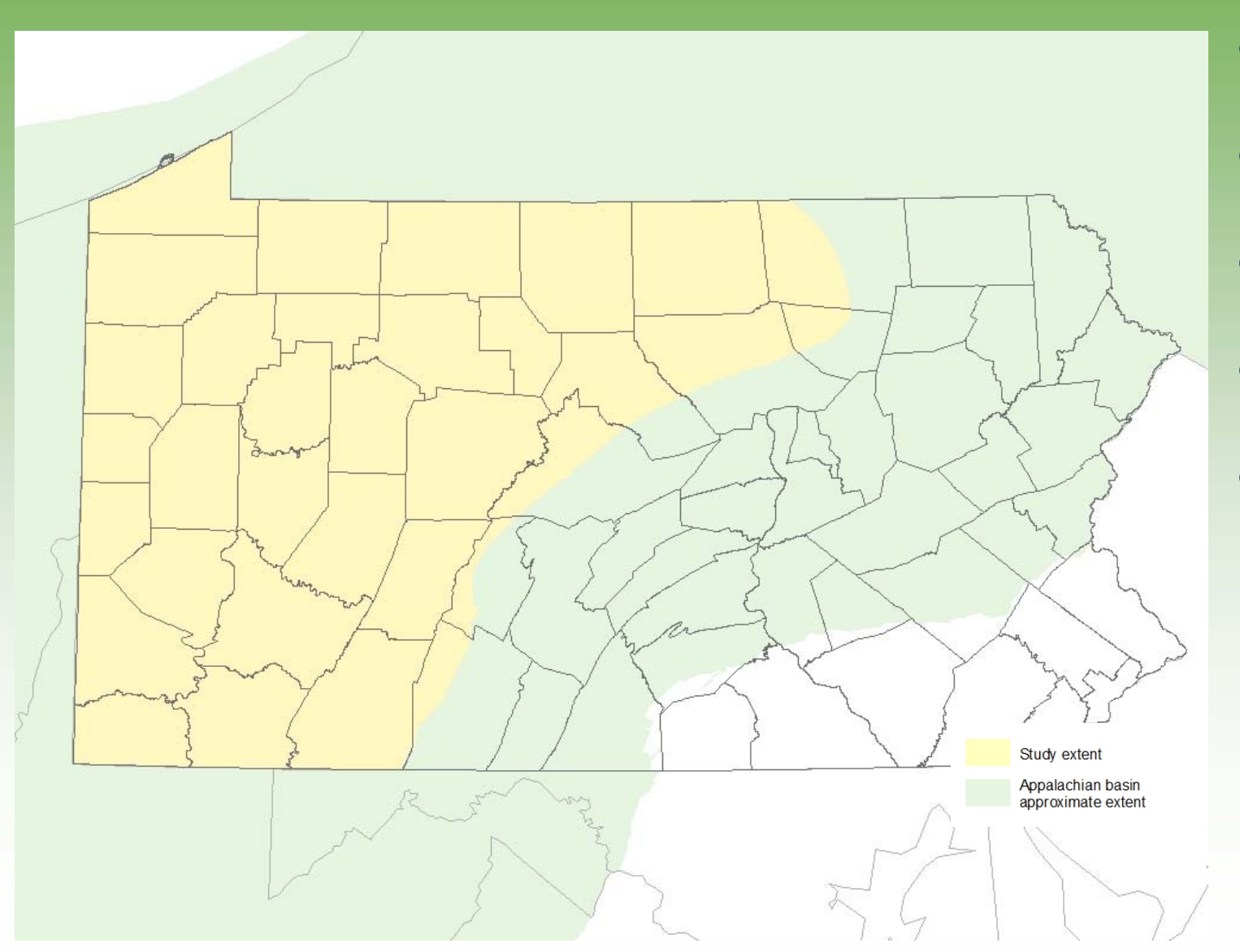

- Shales

- Structures

- TOC results

- Thermal maturity results

- Conclusions 


\section{Upper Devonian Shales}

- West Falls Formation

- Rhinestreet Member

- Genesee Formation

- Geneseo Member

- Harrell Formation

- Burket Member

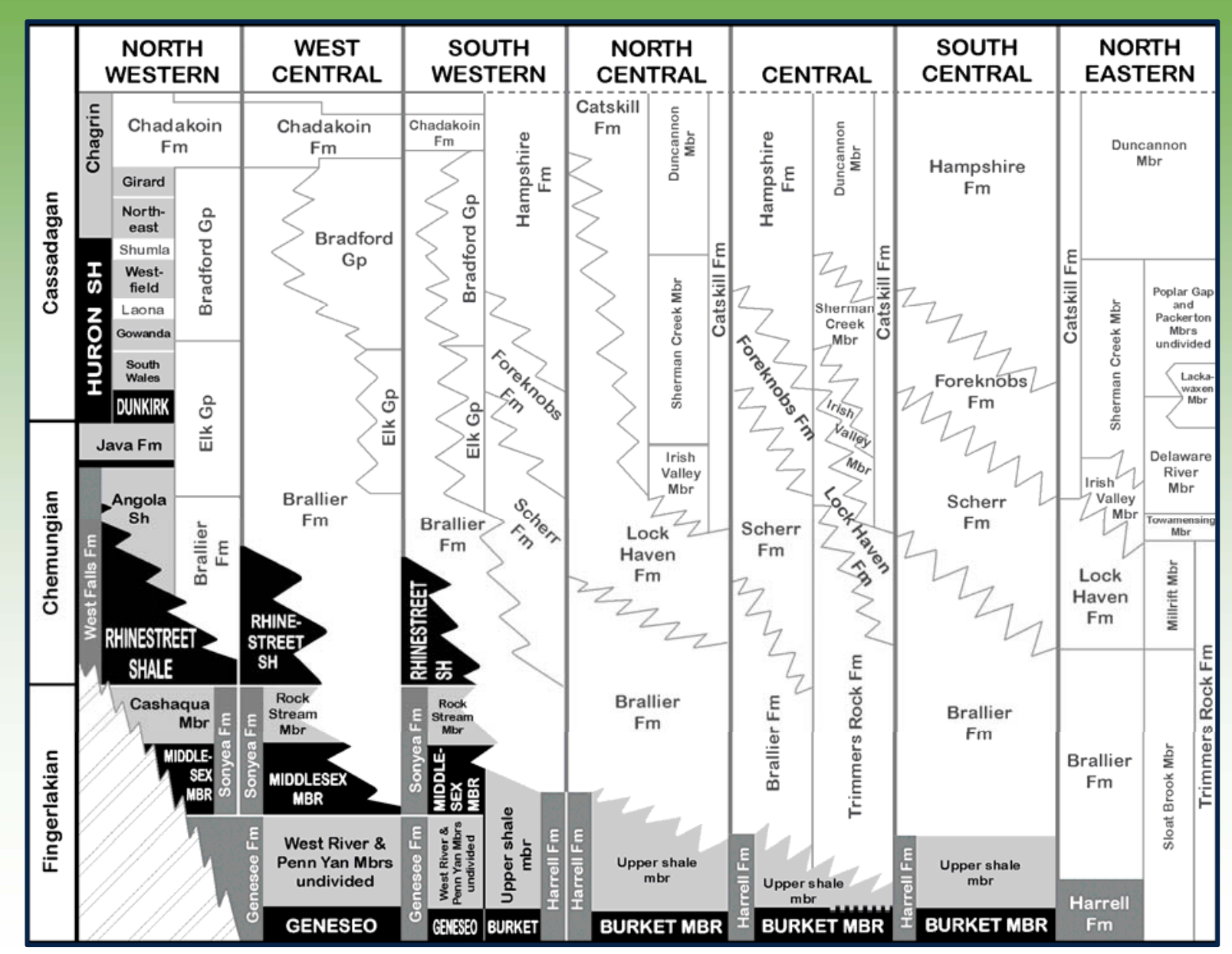




\section{Major Geologic Structures}

- Allegheny Front

- Rome Trough

- Lineaments

I- - Rome Trough

$\square$ Speculated western edge

$\searrow$ Lineament

$\square$ Allegheny structural front

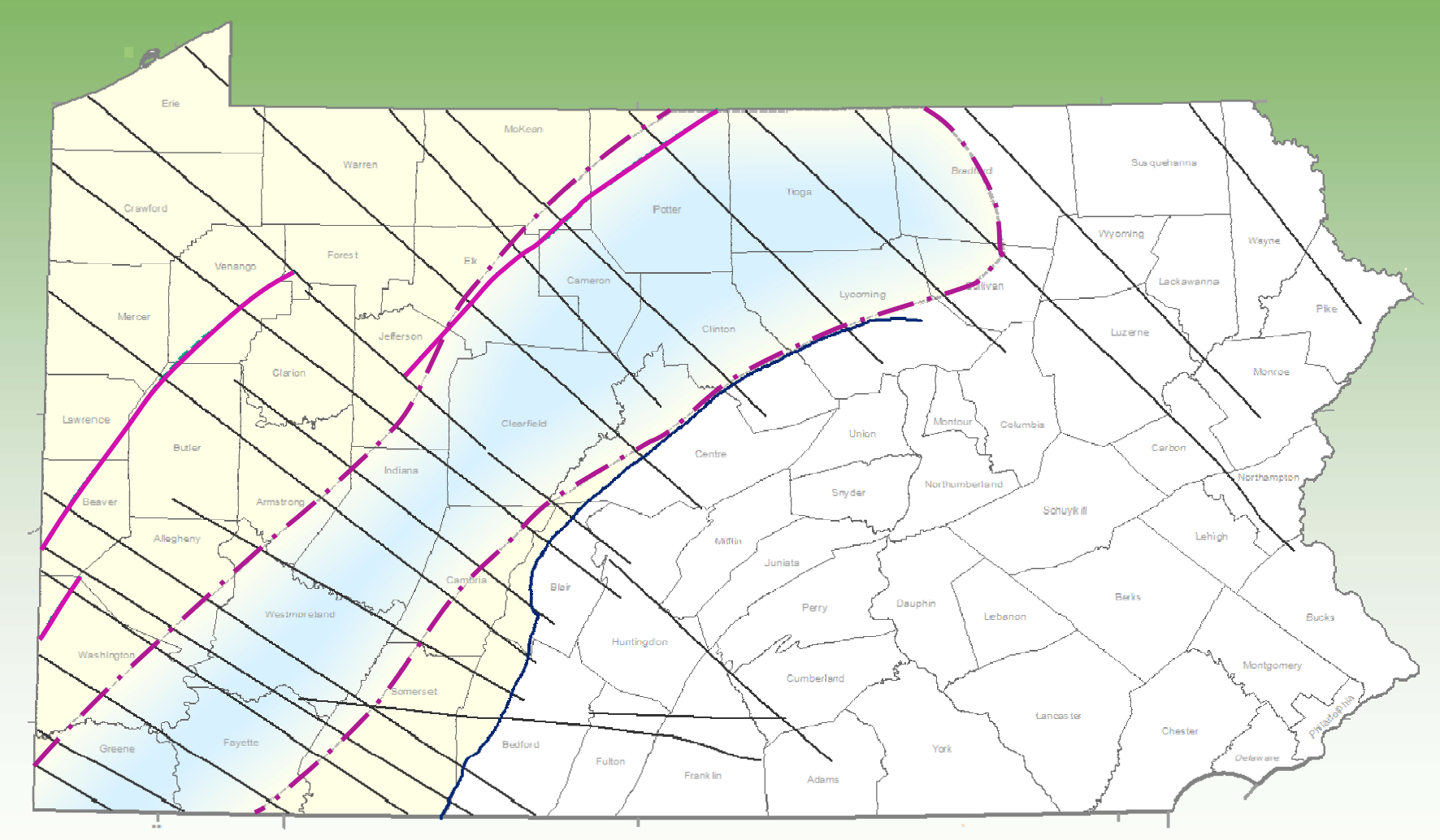




\section{Genesee/Harrell TOC results}

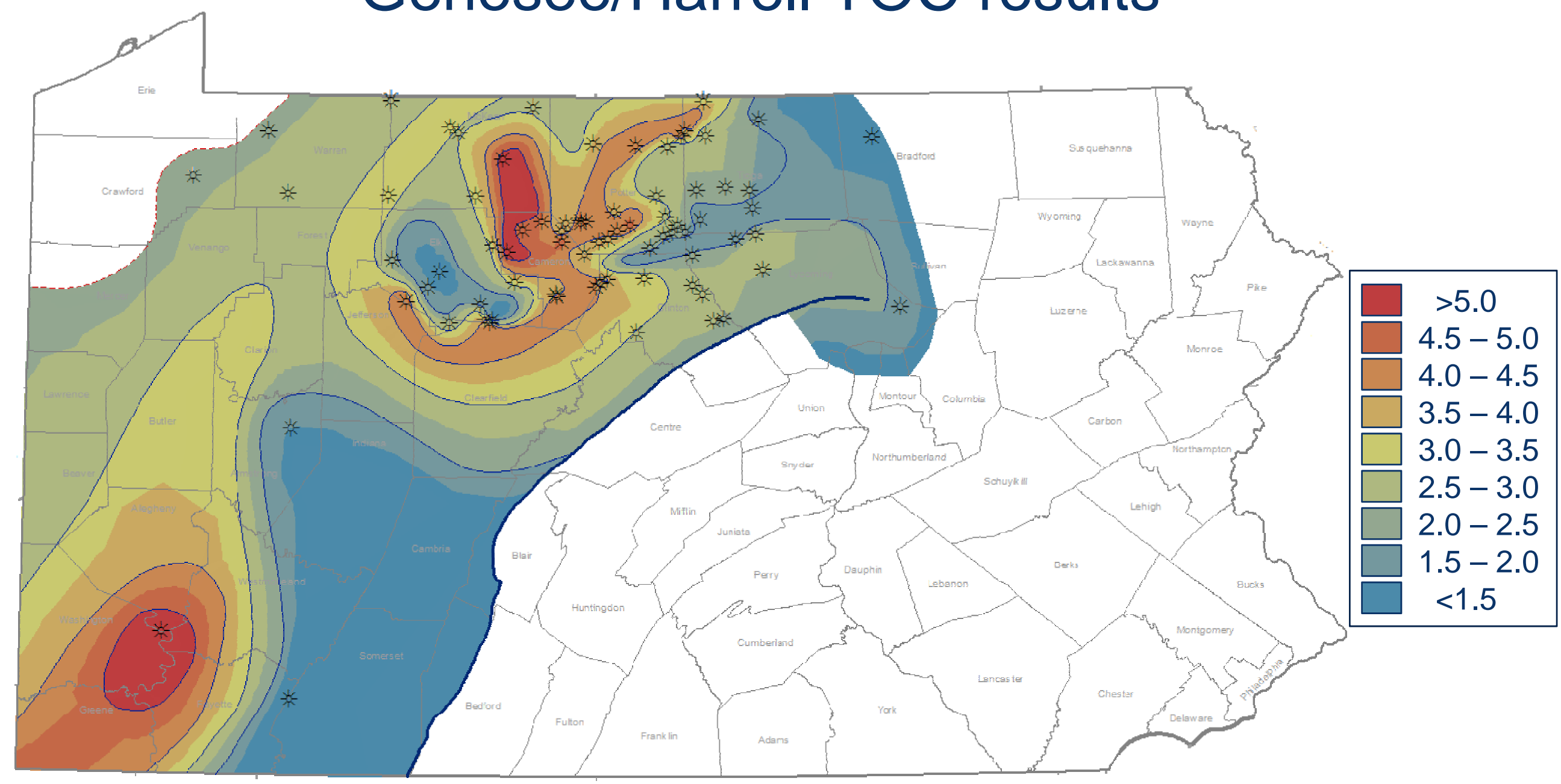




\section{Genesee/Harrell TOC results}

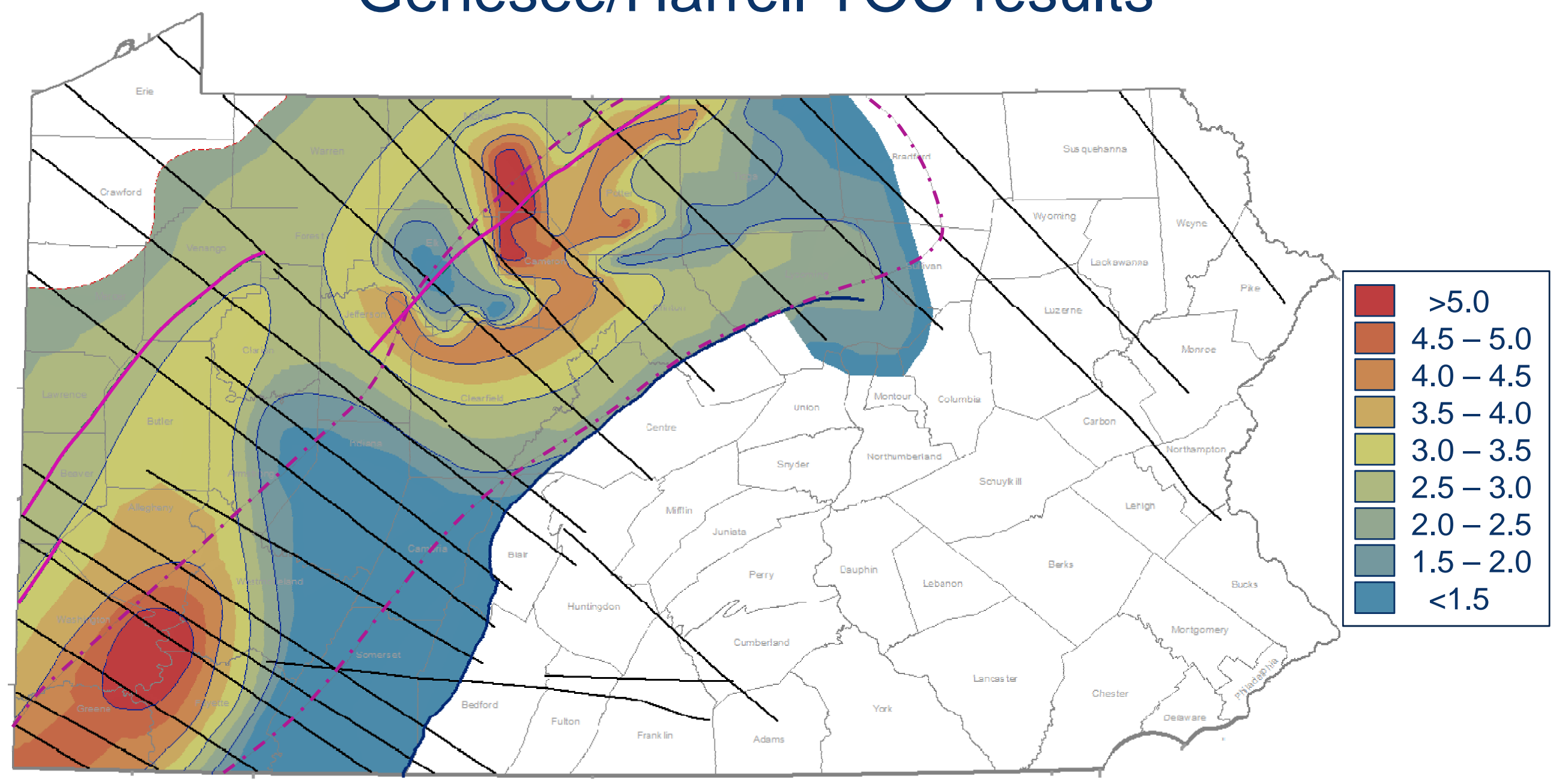




\section{West Falls TOC Results}




\section{West Falls TOC Results}

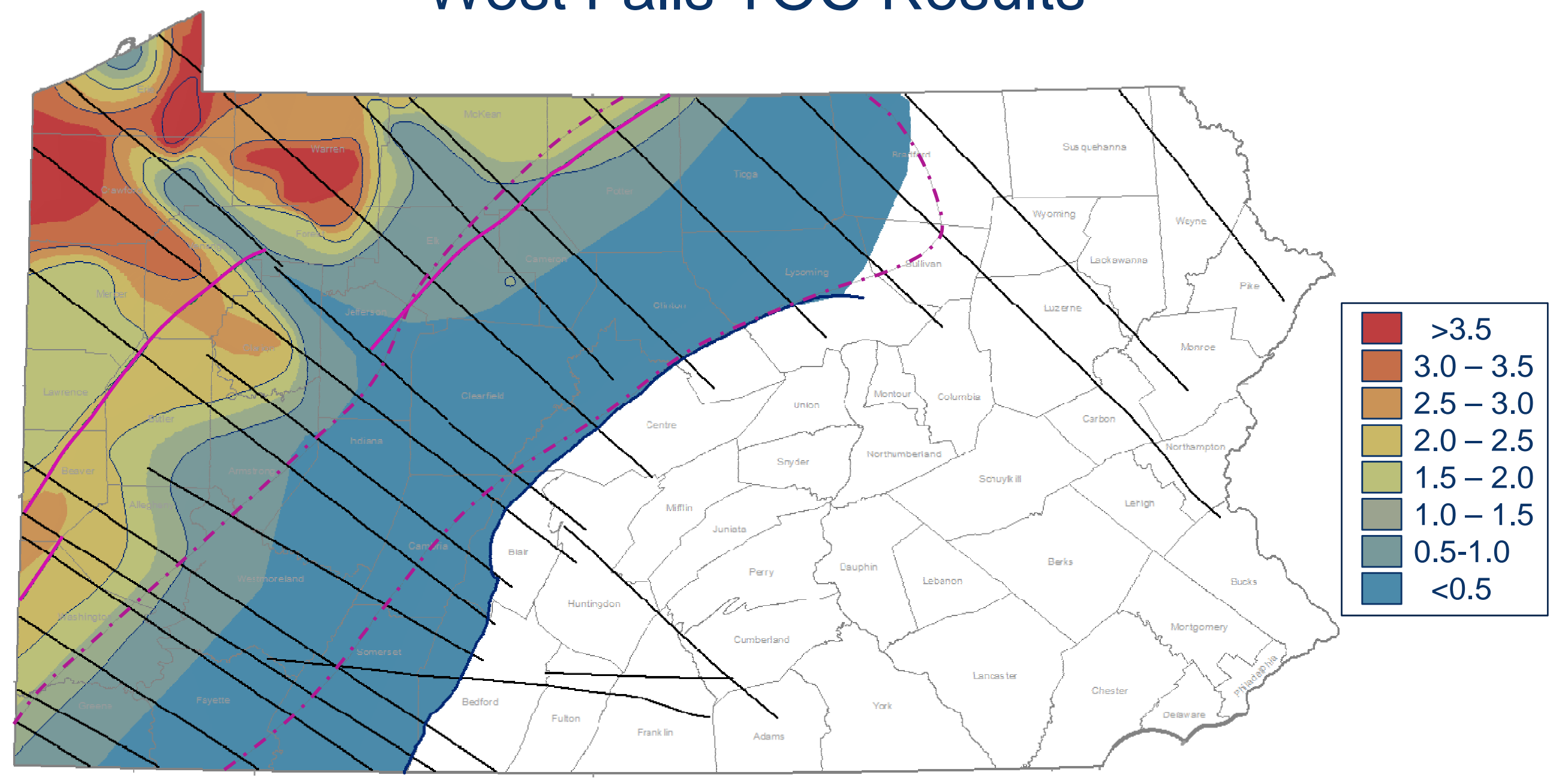




\section{Paleogeography}

\section{Genesee/Harrell time}

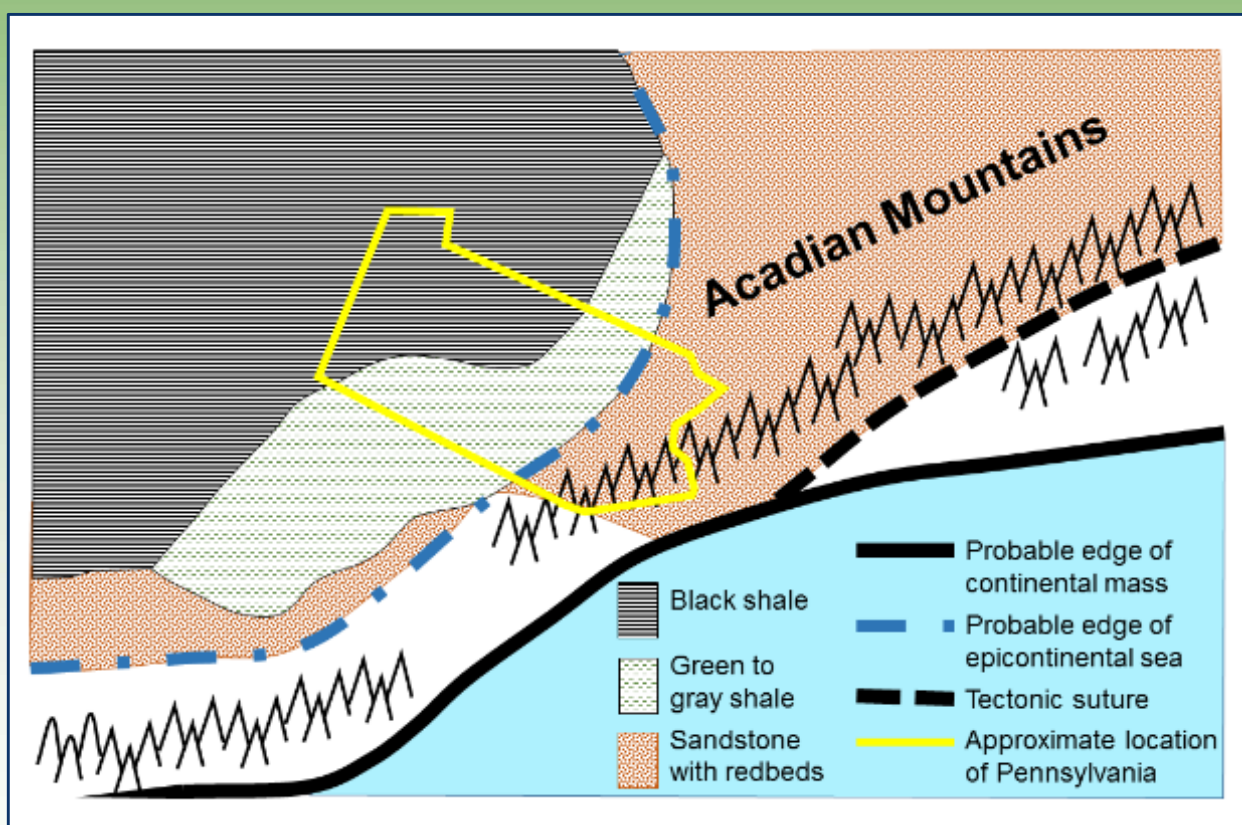

\section{West Falls time}

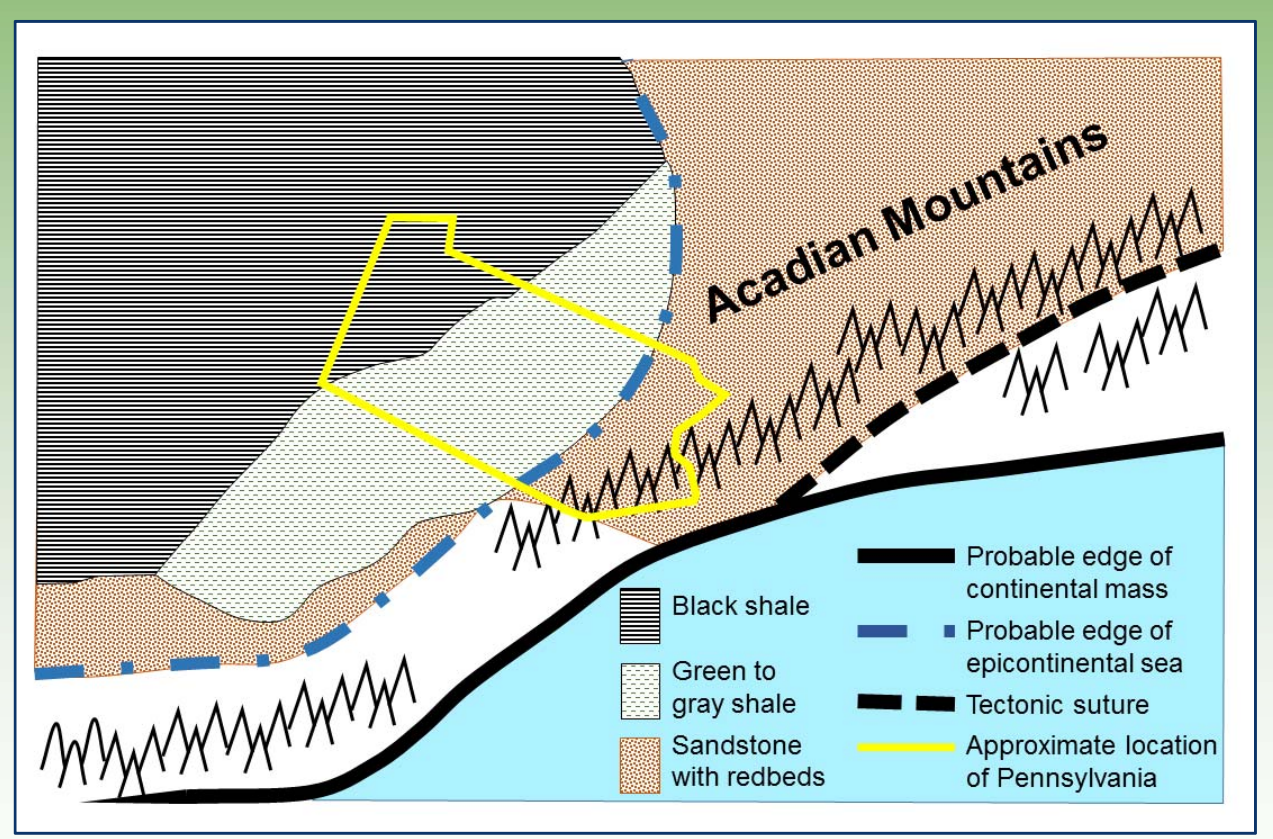




\section{Thermal Maturity Table}

\begin{tabular}{|c|c|}
\hline Maturity Stage & $\mathbf{\%} \mathbf{R}_{\mathbf{0}}$ \\
\hline Immature & $0.20-0.60$ \\
\hline Early Oil & $0.60-0.65$ \\
\hline Peak Oil & $0.65-0.90$ \\
\hline Wet Gas & $0.90-1.50$ \\
\hline Dry Gas & $1.50-2.50$ \\
\hline Overmature & $>2.50$ \\
\hline
\end{tabular}

www.denr.pa.gov 


\section{Genesee/Harrell Thermal Maturity Results}

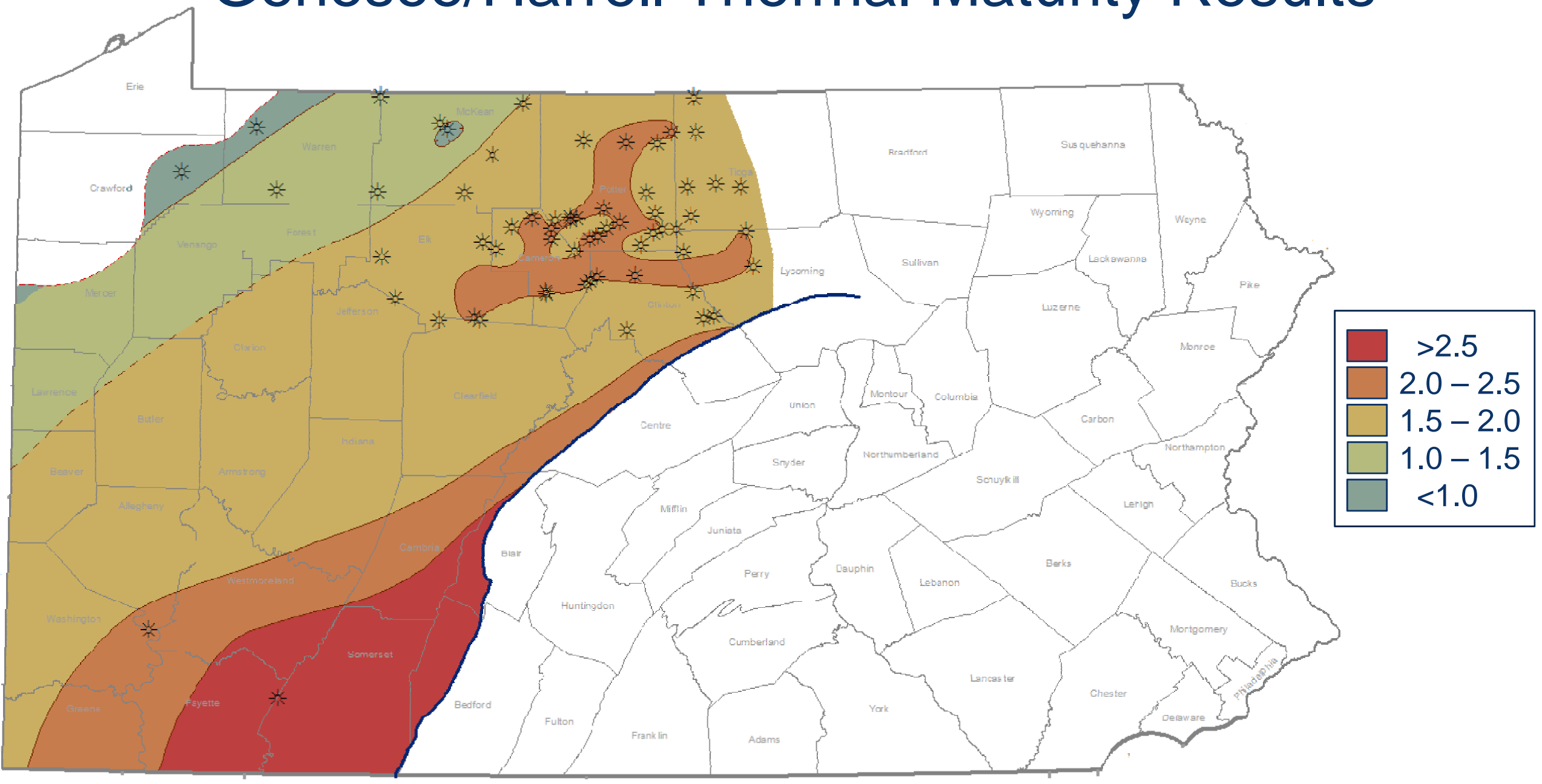




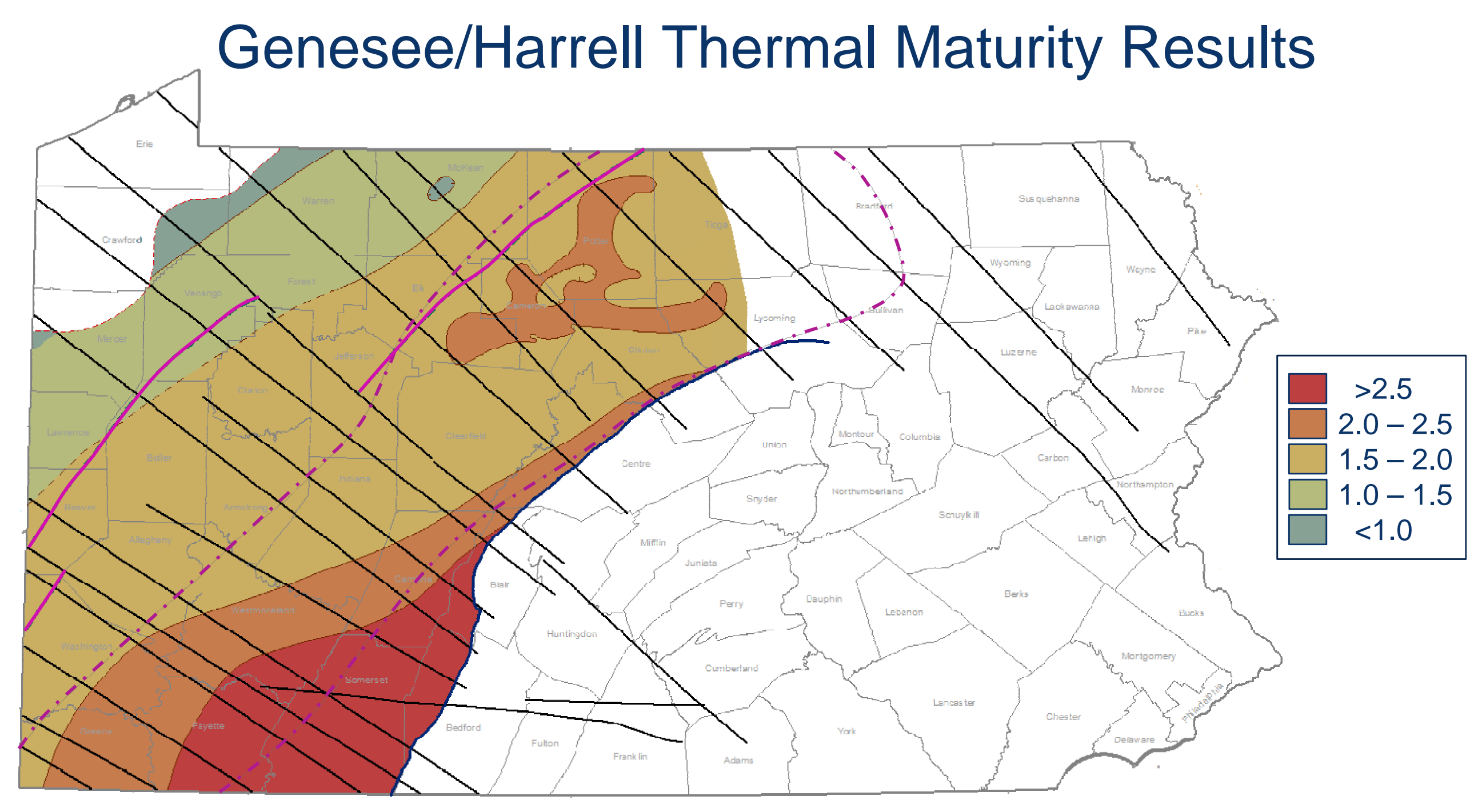




\section{West Falls Thermal Maturity Results}

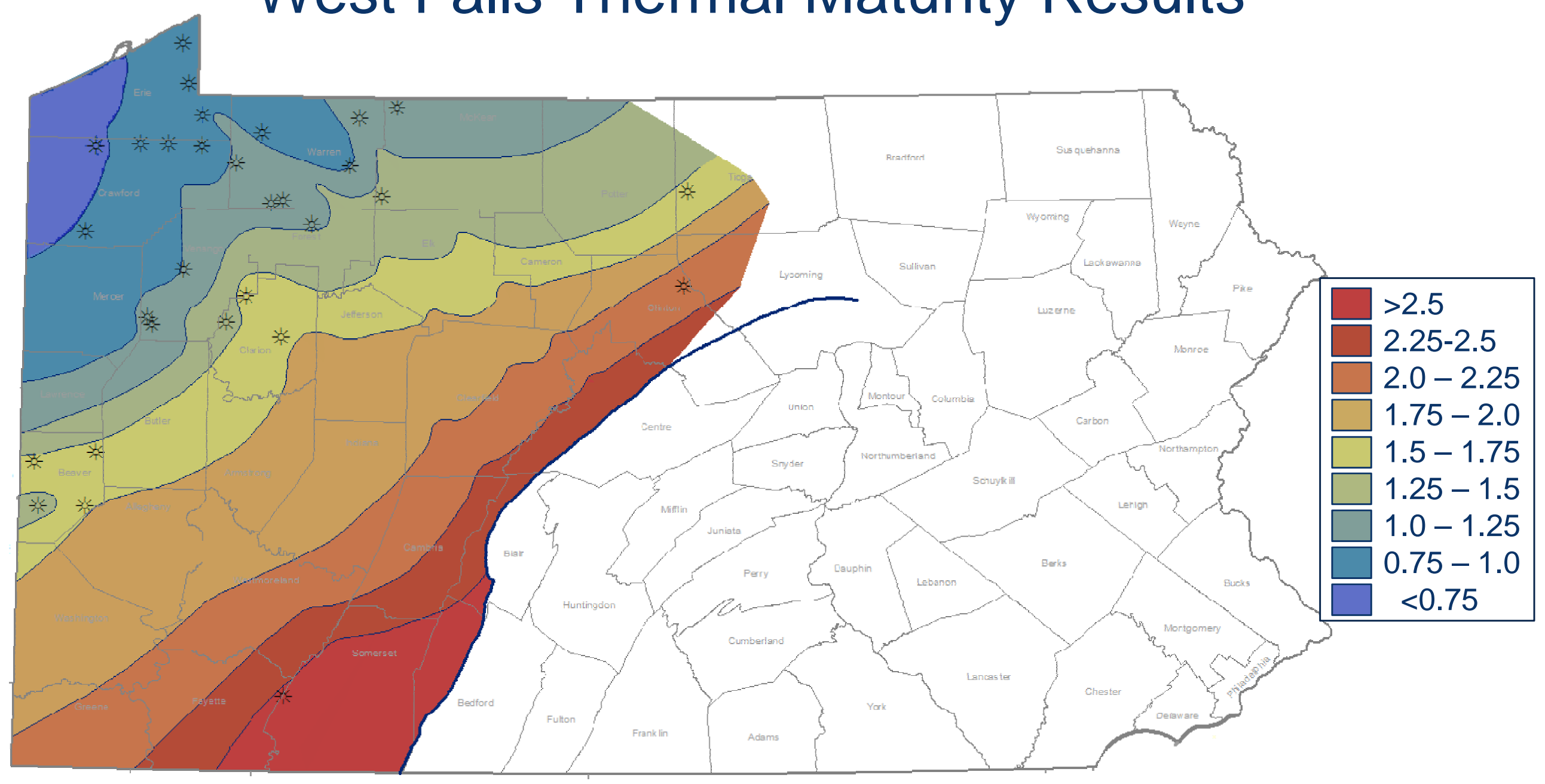




\section{West Falls Thermal Maturity Results}

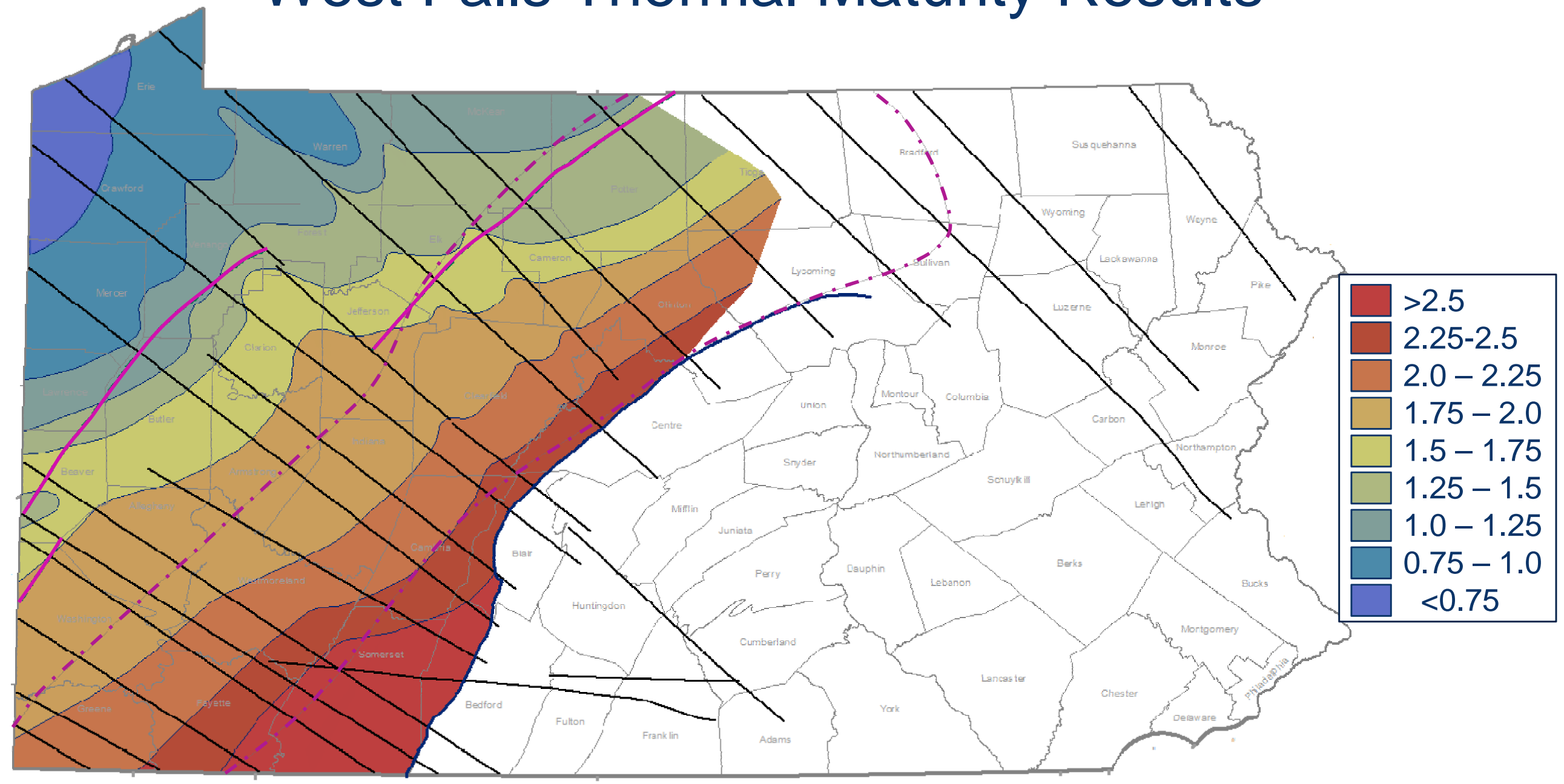




\section{Conclusions}

\section{Genesee/Harrell}

- The Allegheny Front displays strong influence on thermal maturity

- The Rome Trough shows some control on TOC and thermal maturity

- Lineaments show little effect on TOC and thermal maturity

\section{West Falls}

- The Allegheny Front displays strong influence on thermal maturity

- The Rome Trough shows little influence on TOC and thermal maturity

- Lineaments show strong effects on TOC and thermal maturity 


\section{Thank you!}

\section{Questions?}

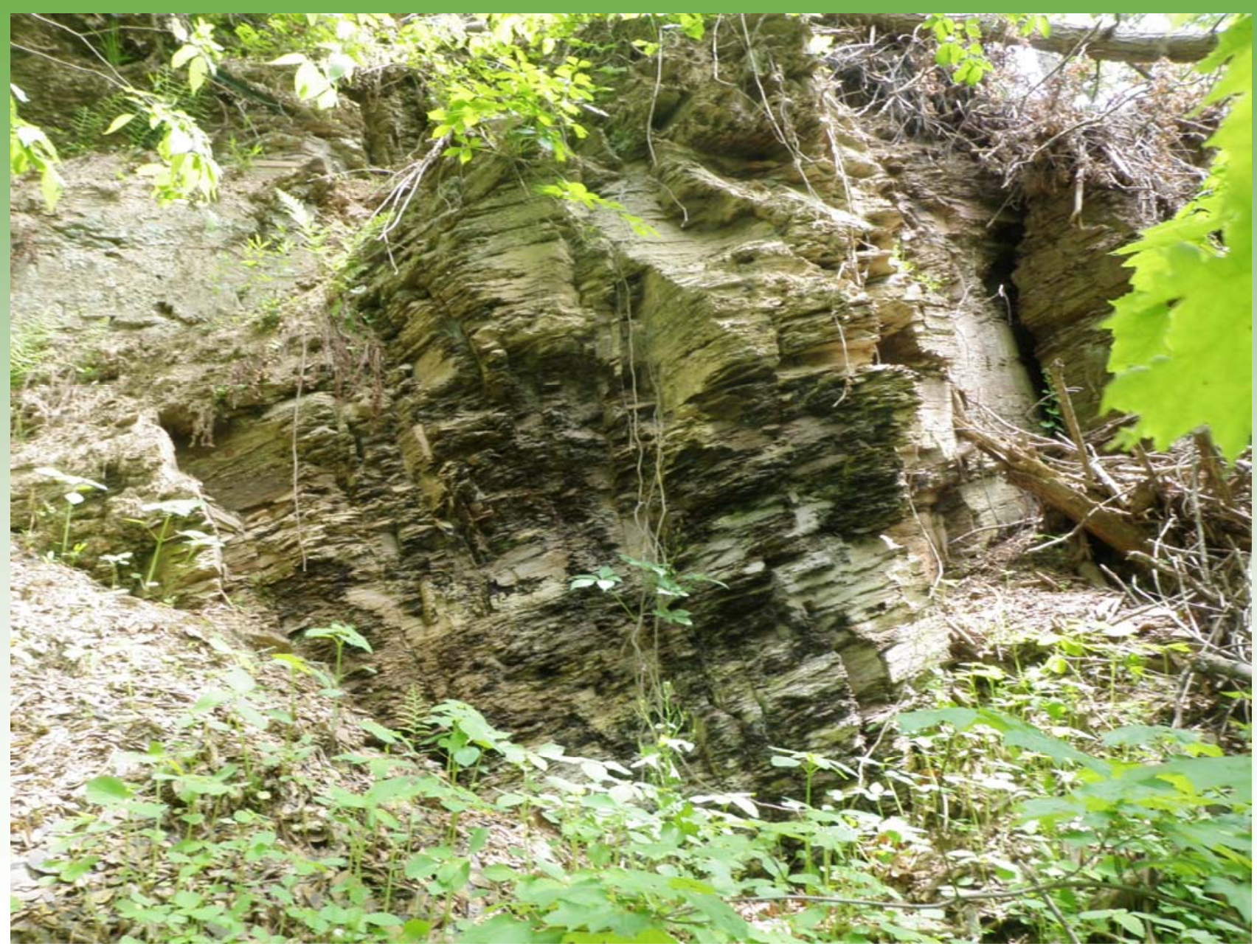

